\title{
PENGEMBANGAN DESA WISATA CANDISARI KECAMATAN SAMBENG KABUPATEN LAMONGANMELALUI BRANDING DAN MEDIAONLINE
}

\section{(DEVELOPMENT OF CANDISARI TOURISM VILLAGE, SAMBENG, LAMONGANTHROUGH BRANDING AND MEDIA ONLINE)}

\author{
Ikhsan Rosyid Mujahidul Anwari ${ }^{1}$, Gayung Kasuma ${ }^{2}$ \\ ${ }^{1,2}$ Departemen Ilmu Sejarah Fakultas Ilmu Budaya Universitas Airlangga \\ e-mail: ikhsan-r-m-a@ fib.unair.ac.id
}

\begin{abstract}
Candisari Village is one of the villages in Sambeng Lamongan District. Candisari village has the potential for the development of tourism with historical branding. The village has a collective memory of the community which, if recorded and retold, will be interesting for educational materials, culinary tourism, forest land in some parts can be developed into an outbound arena, as well as other community activities ie, having a typical papaya production called calina, a sugar cane processing factory brown sugar, and one of the KKN BBM programs that started with the planting of oyster mushrooms and hydproponic vegetables. The various potentials are at least a capital for Candisari Village in arranging it as a Tourism Village. While the main problem in the development of Candisari tourism village at present is the absence of branding and the lack of facilities or publications to introduce it to the community. The purpose of this activity is to improve and develop the potential of Candisari tourism villages to be more productive and bring economic benefits to the village community. The solution used is making brands and making marketing publications through websites and social media. At the end of the activity, the Candisari tourism village community experienced an increase in the quality of life, one of which was the village's potential and tourism.
\end{abstract}

Keywords: branding, Candisari, social media, village tours

\begin{abstract}
abstrak
Desa Candisari merupakan salah satu desa yang terdapat di Kecamatan Sambeng Lamongan. Desa Candisari memiliki potensi untuk pengembangan wisata dengan branding sejarah. Desa memiliki memori kolektif masyarakat yang kalau dibukukan dan diceritakan ulang akan menarik untuk bahan edukasi, wisata kuliner, lahan hutan yang dibeberapa bagian bisa dikembangkan menjadi arena outbond, serta aktifitas masyarakat lainnya yakni, memiliki produksi khas buah pepaya yang disebut calina, pabrik pengolahan tebu menjadi gula merah, dan salah satu program KKN BBM yang mengawali dengan penanaman jamur tiram dan sayur hidproponik. Berbagai potensi tersebut setidaknya menjadi modal bagi Desa Candisari dalam menata sebagai Desa Wisata.Sedangkan persoalan utama dalam pengembangan desa wisata Candisari saat ini adalah masih belum adanya branding dan belum adanya sarana atau publikasi untuk mengenalkan pada masyarakat. Tujuan dari kegiatan ini adalah meningkatkan dan mengembangkan potensi desa wisata Candisari agar lebih produktif dan mendatangkan keuntungan secara ekonomi bagi masyarakat desa. Solusi yang digunakan adalah pembuatan brand dan pembuatan publikasi pemasaran melalui website dan media sosial. Pada akhir kegiatan, masyarakat desa wisata Candisari mengalami peningkatan kualitas hidup salah satunya dengan keberadaan potensi dan wisata desa.
\end{abstract}

Kata kunci: branding, Candisari, desa wisata, media sosial 


\section{PENDAHULUAN}

Pariwisata merupakan industri gaya baru yang mampu memacu pertumbuhan ekonomi yang cepat dalam hal kesempatan kerja, pendapatan, taraf hidup, dan dalam mengaktifkan sektor lain di dalam negara penerima wisatawan (Bagus 1991). Pembangunan di bidang kepariwisataan mempunyai tujuan akhir untuk meningkatkan pendapatan masyarakat yangpada akhirnya dapat meningkatkan kesejahteraan masyarakat (Waluyo 1993). Di sampingitu, pariwisata sebagai suatu sektor yang kompleks mampu menghidupkan sektor-sektorlain meliputi industri-industri seperti kerajinan tangan, cendera mata, penginapan, dan transportasi (Salah \& Wahab 1976). Disebutkan pula bahwa pariwisata sebagai industri jasa yang digolongkan sebagai industri ketiga cukup berperan penting dalam menetapkan kebijaksanaan mengenai kesempatan kerja, dengan alasan semakin mendesaknya tuntutan akan kesempatan kerja yang tetap sehubungan dengan selalu meningkatnya wisata pada masa yang akan datang (Spillane \& James 1993).

Salah satu potensi wisata yang banyak dikembangkan di Indonesia adalah wisata laut atau pantai. Satu sisi penduduk desa-desa pesisir pantai yang sebagian besar bergantung pada mata pencaharian sebagai nelayan dan petani seringkali identik dengan kemiskinan. Nelayan dan petani adalah dua sektor di mana kelompok kemiskinan memiliki angka yang besar. Kelompok petani pedesaan merupakan kelompok terbesar dari penduduk miskin di Indonesia, yaitu 55\%, di mana dari jumlah tersebut kelompok terbesar adalah rumah tangga petani tanaman pangan dan palawija (Arifin 2007).

Desa Candisari memiliki batas wilayahSebelah Utara berbatasan dengan Desa Mogojati Sari, Sebelah Selatan berbatasan dengan Desa Pamotan, Sebeleh Barat dengan Desa Kedung Wangi, dan Sebelah Timur berbatasan dengan Desa Baru rejo. Lahan yang ditempati untuk pemukiman seluas $24,63 \mathrm{ha} / \mathrm{m}^{2}$, memiliki lahan Sawah tada hujan seluas 200,46 ha/m $\mathrm{m}^{2}$,Ladang/Tegalan $15,02 \mathrm{ha} / \mathrm{m}^{2}$, perkebunan seluas $164,5 \mathrm{ha} / \mathrm{m}^{2}$, dan areal hutan $314,30 \mathrm{ha} / \mathrm{m}^{2}$.

Secara umum desa ini memiliku tingkat kesuburan tanah sangat subur seluas $732,64 \mathrm{ha} / \mathrm{m}^{2}$ dan tanah sedang 24,68 ha/ $\mathrm{m}^{2}$.Jarak ke ibu kota Kecamatan $3 \mathrm{Km}$, dengan waktu tempuh 0,25 jam dan jarak ke kabupaten $30 \mathrm{~km}$ dengan waktu tempuh 1 jam. Sedangkan jarak dengan ibukota propinsi sekitar $100 \mathrm{~km}$ dengan waktu tempuh 3 jam.Desa Candisari memiliki potensi perikanan air tawar/darat komoditi Ikan lele 4,8 ton $/ \mathrm{ha} / \mathrm{m}^{2}$, Pemasarannya dilakukan melalui tengkulak.

Dalam bidang pertanian untuk hasil tanaman Palawija komoditi Kedelai luas lahan 10,4 ha/m ${ }^{2}$, Kacang tanah luas lahan $0,5 \mathrm{ha} / \mathrm{m}^{2}$. Menghasilkan $0,8 \mathrm{ton} / \mathrm{ha}^{2} \mathrm{~m}^{2} \mathrm{jika}$ diuangkan Rp. 14.880.000,- kacang panjang $0,2 \mathrm{ha} / \mathrm{m}^{2}$, Jagung luas lahan $72,3 \mathrm{ha} / \mathrm{m}^{2}$, untuk tanaman padi sawah luas lahan $244,1 \mathrm{ha} / \mathrm{m}^{2}$. dengan hasil panen $1900 \mathrm{ton} / \mathrm{ha} / \mathrm{m}^{2}$, tanaman padi ladang dengan luas lahan $160,88 \mathrm{ha} / \mathrm{m}^{2}$, dengan hasil 1120 ton disamping itu juga ada tanaman pisang luas lahan $0,5 \mathrm{ha} / \mathrm{m}^{2}$.Untuk Peternakan ada 655 ekor sapi potong 820 ekor kambing, ayam buras 945 ekor.

Desa Candisari memiliki 895 kepala keluarga (KK). Jumlah penduduk Desa Candisari tahun 2017 sebanyak 3420 Jiwa sedangkan untuk tahun 2016 sebanyak 3349 Dengan struktur mata pencarian, Petani sebanyak830 orang, Ada sebanyak 21 PNS (Pegawai 
Negeri sipil) dan 4 warga Desa Candisari yang menjadi anggota TNI/POLRI. 14 orang menjadi guru, 1 orang bidan. Jumlah penduduk usia 18-56 yang belum bekerja sebanyak 753 orang sedangkan jumlah angkatan kerja usia 18-56 tahun sebanyak 1538 orang. Jumlah penduduk Usia 7-18 tahun yang masih sekolah sebanyak 418 orang.

Dalam bidang kesejahteraan Penduduk Jumlah keluarga Prasejahtera 162 KK, Keluarga Sejahtera I sebanyak 148 KK, Keluarga sejahtera II $180 \mathrm{KK}$, keluarga sejahtera III 165 KK dan Keluarga Sejahtera III Plus sebanyak 240 KK. Dalam bidang Ekonomi Masyarakat Produk Domestik bruto tahun ini untuk pertanian Rp.9.063.975.000,Perkebunan Rp.155.000.000,- Penduduk Desa Candisari yang memiliki kendaraan bermotor roda dua sebanyak $650 \mathrm{KK}$. Pemilik kendaraan roda empat/lebih sebanyak $36 \mathrm{KK}$, Sedangkan pemilik pesawat TV $625 \mathrm{KK}$. Untuk bangunan rumah menurut dinding tembok sebanyak 442 buah, dinding kayu 444 buah sedangkan rumah Bambu ada 9 buah.

Desa Candisari merupakan salah satu desa yang terdapat di Kecamatan Sambeng Lamongan. Sampai saat ini, desa ini telah dijadikan sebagai lokasi penempatan KKN BBM oleh Universitas Airlangga. Desa ini memiliki 6 (enam) dusun yakni Cane, Nongko, Kandangan, Resik, Gampeng, dan Kedungwaru. Beberapa program kegiatan KKN BBM yang telah dilaksanakan masih berkutat pada persoalan perekonomian, pendidikan, sosial, dan kesehatan. Padahal di Desa Candisari memiliki potensi untuk pengembangan wisata dengan branding sejarah.

Desa Cane memiliki catatan sejarah ketika masa kerajaan Majapahit. Dimana nama Cane tercatat dalam prasasti Cane yang sekarang tersimpan di Museum Nasional Jakarta. Berangkat dari memori kolektif dari cerita historis tersebut masyarakat setempat juga sudah memiliki ide kreatif untuk menjadikan sebagai desa wisata berbasiskan sejarah. Beberapa potensi yang sangat mendukung dalam pengembangan menjadi desa wisata terlihat dari keberadaan cerita historis dusun Cane sebagai tempat ditemukannya prasasti Cane (sekarang disimpan di Museum nasional Jakarta), memori kolektif masyarakat yang kalau dibukukan dan diceritakan ulang akan menarik untuk bahan edukasi, wisata kuliner, lahan hutan yang dibeberapa bagian bisa dikembangkan menjadi arena outbond, serta aktifitas masyarakat lainnya yakni, memiliki produksi khas buah pepaya yang disebut calina, pabrik pengolahan tebu menjadi gula merah, dan salah satu program KKN BBM yang mengawali dengan penanaman jamur tiram dan sayur hidproponik. Berbagai potensi tersebut setidaknya menjadi modal bagi Desa Candisari dalam menata sebagai Desa Wisata.

Namun potensi tadi menghadapi beberapa kendala yakni lokasi yang jauh berjarak 30 $\mathrm{km}$ dari pusat kota kabupaten $(30 \mathrm{~km})$ dan membutuhkan waktu sekitar 60 menit dari jalan raya kabupaten. Masyarakat di desa Candisari memiliki ide kreatif untuk menjadikan desa wisata dengan mendirikan cafe kuliner, memberikan nama jalan berdasarkan pada cerita sejarah, dan persiapan arena outbond. Namun kegiatan warga masih belum terkoordinasi dengan baik karena belum muncul komunitas masyarakat yang sadar wisata. Sedangkan peluang untuk lebih mengembangkan dan meningkatkan wisata di desa ini sangat besar. Dari gambaran analisis situasi tersebut diatas 
permasalahan dari desa wisata Candisari Kecamatan Sambeng kabupaten Lamongan berkaitan dengan aspek branding dan marketing produk desa wisata.

\section{METODE PENGABDIAN MASYARKAT}

Pendekatan yang akan ditawarkan dari kegiatan ini adalah suatu kerjasama pendampingan kewirausahaan sektor wisata desa, melibatkan masyarakat, pemangku kepentingan di tingkat desa Candisari dan tim Universitas Airlangga. Kegiatan yang dilakukan meliputi:

\section{Penyuluhan}

Penyuluhan dilakukan melalui kerjasama dengan Dinas Kebudayaan dan Pariwisata Propinsi Jawa Timur karena telah memiliki pengalaman secara formal dalam program dan kegiatan pengembangan pariwisata di lingkup propinsi Jawa Timur. Dinas sebagai mitra II memberikan materi bagaimana langkah-langkah dan strategi yang harus dilakukan dalam kesuksesan peningkatan desa wisata. Materi penyuluhan didasarkan pada temuan masalah guna peningkatan dan pengembangan desa wisata yakni pembentukan komunitas masyarakat sadar wisata, materi tentang branding, dan materi tentang publikasi pemasaran memanfaatkan IT melalui website dan jejaring media sosial

\section{Praktek Demonstrasi}

Praktek demontrasi pembuatan brand dan publikasi melalui leaflet, website, serta media sosial. Masyarakat diajari dan dipandu untuk pembuatan branding melalui pembuatan leaflet, website, dan publikasi media social, serta dengan diselingi oleh pembuatan produk-produk potensi usaha yang dapat mendukung kegiatan wisata.

\section{Pembangunan Teknis}

Pemberian bantuan untuk sarana dan prasaran wisata dibantu dengan swadaya masyarakat. Tim pengabdian bersama-sama dengan masyarakat membangun fasilitas yang berguna untuk wisata seperti gazebo di lapangan, gapura, serta toilet.

\section{HASIL DAN PEMBAHASAN}

Desa Candisari merupakan salah satu desa yang terdapat di Kecamatan Sambeng Lamongan. Desa ini memiliki 6 (enam) dusun yakni Cane, Nongko, Kandangan, Resik, Gampeng, dan Kedungwaru. Desa Candisari memiliki potensi untuk pengembangan wisata dengan branding sejarah. Sehingga program pengabdian masyarakat ini dijadikan salah satu program unggulan di Desa Candisari.

Dusun Cane Desa Candisari memiliki catatan sejarah ketika masa kerajaan Majapahit. Dimana nama Cane tercatat dalam prasasti Cane yang sekarang tersimpan di Museum Nasional Jakarta. Berangkat dari memori kolektif dan cerita historis tersebut masyarakat setempat juga sudah memiliki ide kreatif untuk menjadikan sebagai desa wisata berbasiskan sejarah. Beberapa potensi yang sangat mendukung dalam pengembangan menjadi desa wisata terlihat dari keberadaan cerita historis dusun Cane sebagai tempat ditemukannya prasasti Cane (sekarang disimpan di Museum nasional Jakarta), memori kolektif masyarakat yang kalau dibukukan dan diceritakan ulang akan menarik untuk bahan edukasi, wisata kuliner, lahan hutan yang dibeberapa bagian bisa dikembangkan 
menjadi arena outbond, serta aktifitas masyarakat lainnya yakni, memiliki produksi khas buah pepaya yang disebut calina, pabrik pengolahan tebu menjadi gula merah, dan salah satu program KKN BBM yang mengawali dengan penanaman jamur tiram dan sayur hidproponik. Berbagai potensi tersebut sebagai modal penting bagi Desa Candisari untuk dikembangkan sebagai Desa Wisata.

Tantangan yang saat ini dihadapi Desa Candisari adalah lokasinya yang berjarak 30km dari pusat kota kabupaten dan untuk masuk ke lokasi membutuhkan waktu sekitar 60 menit dari jalan raya kabupaten dengan akses jalan yang belum diperbaiki. Selain itu, akses telekomunikasi juga menjadi tantangan tersendiri karena kekuatan sinyal cukup lemah di wilayah ini.

Beberapa produk wisata bermasalah dalam aspek branding produk dan belum adanya sarana publikasi untuk mengenalkan pada masyarakat. Sehingga tim bekerjasama dengan Dinas Kebudayaan dan Pariwisata Propinsi Jawa Timur telah melakukan penyuluhan dan pendampingan terhadap mitra I. Materi yang disampaikan adalah perencanaan branding dan penyiapan sarana publikasi melalui website dan social media. Tujuan dari kegiatan ini adalah meningkatkan dan mengembangkan potensi desa wisata Candisari agar lebih produktif dan mendatangkan keuntungan secara ekonomi bagi masyarakat desa. Target khusus dari kegiatan ini adalah pengembangan desa wisata melalui pembentukan komunitas masyarakat sadar wisata, branding dan media publikasi berbasiskan website dan media sosial. Secara garis besar, pelaksanaan teknis kegiatan ini menyasar pada produk desa wisata yang meliputi:

\section{Bumi Perkemahan Mahoni Raya}

Bumi Perkemahan Mahoni Raya yang terletak di Desa Candisari kini mulai aktif dipergunakan kembali. Bumi perkemahan tersebut terletak di dusun Nongko, lokasi tersebut terbilang strategis untuk pembangunan bumi perkemahan karena berada di pinggir jalan beserta di kelilingi oleh pohon-pohon yang besar nan rindang. Selain itu, di Bumi perkemahan terdapat sebuah lapangan yang menambah kesan area perkemahan yang dapat dijadikan sebagai area outbond atau sebagainya. Di bumi perkemahan mahoni raya sendiri saat ini telah berdiri bangunan pendopo dan mck (mandi cuci kakus) untuk staf sekretariat bumi perkemahan. Pembangunan tersebut dilakukan demi menambah sarana dan prasarana sebagai persyaratan terbentuknya bumi perkemahan yang nantinya dapat dijadikan sebagai tempat perkemahan para peserta pramuka atau lainnya. Tujuan didirikannya fasilitas di bumi perkemahan sendiri adalah untuk mengembangkan dan memperbaiki fasilitas - fasilitas bumi perkemahan yang sebelumnya belum ada untuk memberikan kenyamanan bagi pengguna bumi perkemahan itu sendiri.

Dengan dibangunnya kembali area perkemahan menambah nilai plus sendiri bagi desa Candisari. Selain dapat dijadikan sebagai area perkemahan, Area Bumi Perkemahan Mahoni Raya juga dapat dijadikan sebagai salah satu ikon dari desa Candisari supaya lebih di kenal oleh masyarakat luar. Kegiatan pembangunan fasilitas bumi perkemahan Mahoni Raya mulai dilaksanakan sejak tanggal 06 Juli 2018 yang mana meliputi proses survei tempat beserta kerja bakti dalam pembangunan pendopo dan mck (mandi cuci kakus) di dusun Nongko, Candisari pada pukul 08:30 - 11:00. Selain pendopo dan mck, di bumi perkemahan Mahoni Raya juga tersedia sebuah gazebo untuk bersantai dan 
dilengkapi dengan beberapa fasilitas outbond untuk anak kecil seperti hammock, atau jaring laba-laba.

Pada hari berikutnya, kegiatan yang dilakukan di bumi perkemahan mahoni raya yakni berupa kerja bakti dalam membersihkan lokasi tersebut. Dalam kegiatan kerja bakti ini banyak pihak yang turut andil, seperti masyarakat sekitar, aparat desa dan tim dari Universitas Airlangga termasuk mahasiswa yang sedang KKN yang bertempat di desa Candisari, dengan harapan program pembangunan dapat terealisasikan dengan cepat dan dengan hasil yang maksimal. Dengan adanya kegiatan dan usaha meningkatkan fasilitas di bumi perkemahan ini diharapkan akan membawa nama desa Candisari hingga ke lingkup masyarakat luar, agar dapat dikenal dengan bumi perkemahannya yang lengkap dan luas. Dengan begitu dapat meningkatkan minat pengunjung terhadap Desa Candisari sebagai tujuan desa wisata.
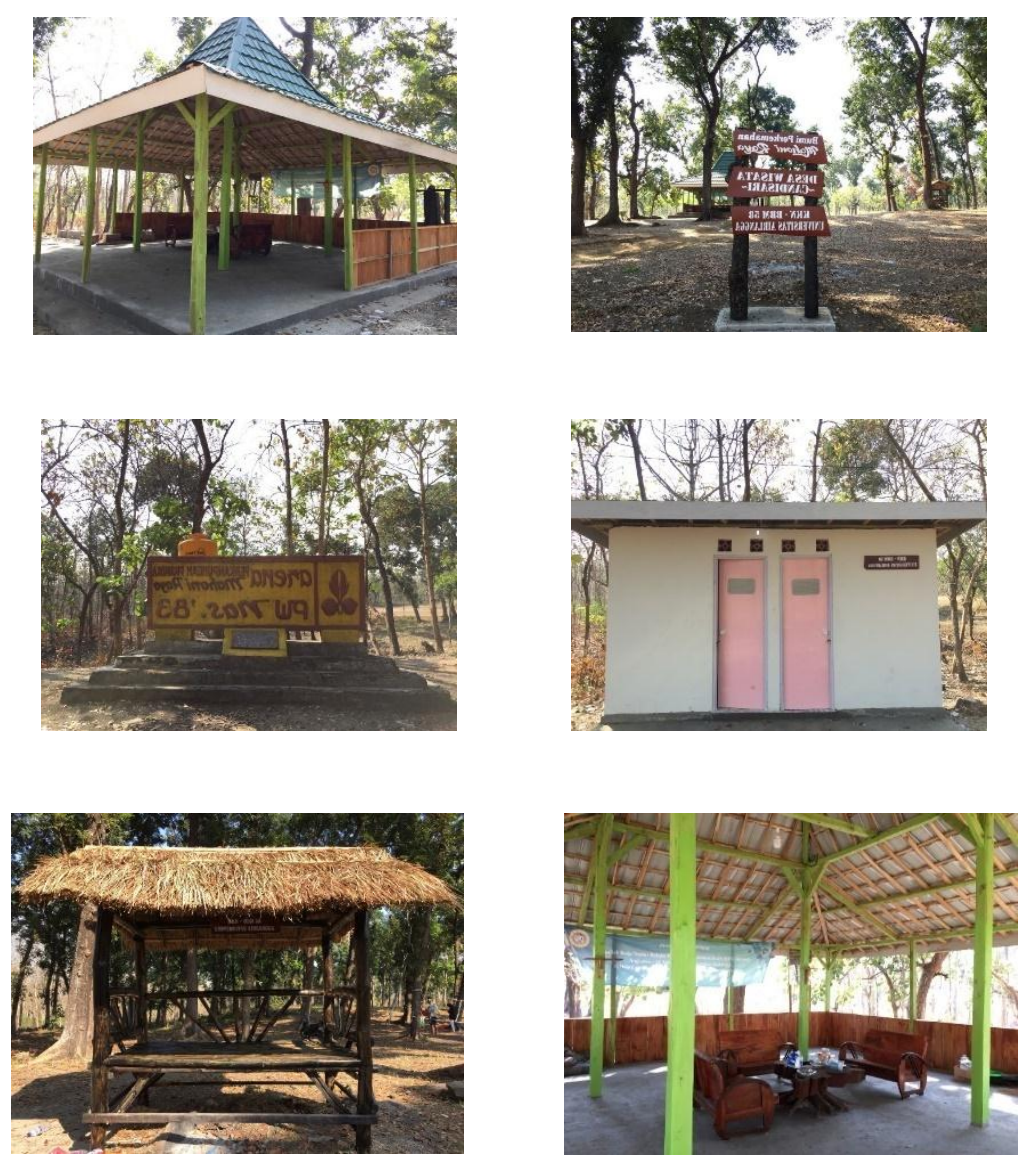

Gambar 3. Bumi Perkemahan Mahoni Raya

\section{Pengolahan Labu (waluh) dan Pandan menjadi produk bernilai Nugget Waluh}

Dusun Kedungwaru memiliki potensi ekonomi dalam bidang pertanian, salah satunya adalah buah labu yang sering disebut waluh. Warga biasa mengolah waluh menjadi berbagai macam olahan masakan seperti; roti goreng waluh, kolak waluh serta jenang waluh. Dalam rangka meningkatkan daya jual waluh, kami mengusulkan sebuah olahan baru kepada Karang Taruna, yaitu nugget waluh. Ide nugget waluh kami adopsi dari 
pisang nugget yang sedang menjadi tren di kota-kota besar. Setelah dilakukan percobaan, nugget waluh disambut baik oleh warga dan akan menjadi prospek yang baik.

\section{Puding Susu Waluh (Puding Sual)}

Puding susu waluh merupakan produk andalan Dusun kedungwaru, Desa Candisari yang berasal dari campuran waluh dan susu. Proses pembuatan puding waluh sangat tradisional yaitu berawal dari mengukus waluh dengan menggunakan tungku. Waluh yang telah matang dihancurkan hingga halus. Selanjutnya waluh yang telah halus ditambahkan dengan bubuk agar-agar dan air. Lalu semua bahan dididihkan dan diaduk hingga tercampur rata. Campuran adonan puding yang telah mendidih didiamkan hingga mendingin untuk kemudian dimasukkan kedalam botol. Botol yang telah terisi dimasukkan kedalam kulkas sampai berbentuk puding. Kemudian memasukkan susu sebagai pelengkap puding susu. Puding susu dikemas dengan menarik dan dijual.

\section{Tikar Pandan}

Tikar pandan merupakan salah satu produk andalan Dusun Kedungwaru, Desa Candisari. Tikar pandan kebanyakan dibuat oleh Ibu rumah tangga dengan material utama berupa daun pandan yang diperoleh dari hutan disekitar Dusun Kedungwaru. Pembuatan tikar pandan dimulai dengan menjemur daun pandan untuk mengurangi kadar air dalam daun tersebut. Selanjutnya daun pandan yang telah dijemur dikebaskan untuk memudahkan proses penganyaman. Daun pandan selanjutnya dilakukan penganyaman dengan ukuran maksimal $2 \times 1 \mathrm{~m}$. Kemudian tikar yang telah dianyam, dirapikan dengan menjahit seluruh pinggiran tikar pandan dan tikar siap untuk dipasarkan. Tikar pandan dipasarkan dengan harga Rp. 30.000.

\section{Villa Cani Sebagai Produk Unggulan Dusun Cani}

Dusun Cani merupakan dusun yang paling dekat dengan balai desa Candisari. Tidak jarang dusun Cani dijadikan sebagai mahkota desa Candisari. Salah satu objek yang unggul di dusun Cani adalah Villa Cani merupakan produk unggulan bagi warga dusun Cani, villa cani sendiri merupakan tempat wisata, kuliner, dan caffe. Villa cani dilengkapi dengan berbagai fasilitas yang kekinian. Seperti: wifi, semua tahu bahwa di dusun Cani yang sulit ditemukan signal, tidak heran apabila warga banyak yang nongkrong di villa cani, selain itu, ada beberapa kuliner unggulan di villa cani, seperti ceker pedas, bebek cani, tidak lupa kopi, dan beberapa kuliner lainnya.

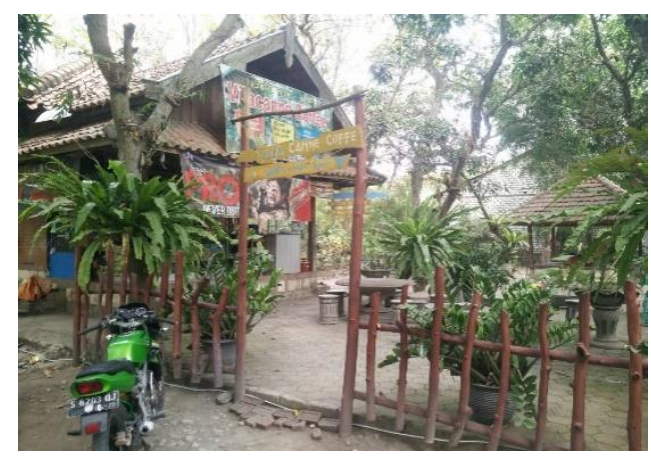

Gambar 4. Villa Cane 
Villa cani letaknya yang cukup strategis berada di tengah-tengah dusun Cani, karena letaknya yang strategis, villa cani tidak sulit dijangkau, bahkan dengan berjalan kaki pun sudah bisa dijangkau dengan waktu yang tidak lama. Selain sebagai basecamp oleh warga dusun Cani, villa cani memiliki banyak manfaatnya, salah satunya sebagai tempat rapat para orang-orang penting, karena fasilitas yang mendukung dilengkapi kuliner kekinian yang membuat villa cani ini menjadi daya tarik untuk masyarakat dusun Cani khususnya dan umumnya untuk warga dusun lain.

Selain itu, villa cani juga dapat menghasilkan nilai ekonomis bagi penjaga atau penjualnya, keekonomisannya yang baik sehingga layak dijadikan usaha yang semakin lama semakin berkembang. Berkat ide-ide cantiknya untuk mengembangkan tempat yang mulanya rata dengan tanah, kini menjadi tempat yang cantik, indah,sungguh eksotis keindahannya. Sehingga Begitu layaknya dengan julukan cantik diberikan untuk tempat villa Cani ini. Warna alam yang berwarna itu, tidak pernah pelik dalam bayangan setiap pengunjung yang datang. Karena indahnya, botaknya alam ini menjelma menjadi alam surgawi di tengah-tengah dusun Cani. Memanjakan manusia yang didekatnya, villa Cani yang populer, bukan hanya eksotisnya, berharganya villa cani pun begitu agung bagi warga dusun Cani.

Masyarakat Resik mempunyai produk unggulan berupa hasil budidaya lele. Untuk produk dari lele sendiri mulanya berawal dari salah satu warga yang memiliki budidaya lele, kemudian mencoba untuk berinovasi dengan memanfatkan ikan lele tersebut menjadi sebuah produk olahan makanan dan hasil akhir cukup sukses, maka dari itu banyak warga yang satu persatu juga ikut memanfaatkan budidaya lele ini untuk dipasarkan. Sehingga dusun Resik memiliki sebutan dengan "Kampung Lele". Untuk hasil pengolahan dari lele dapat berupa makanan olahan seperti nugget, bakso, keripik. Hasil produk ini ternyata sudah dikenal sampai luar Desa Candisari dan menjadi peringkat ke-3 se-Jawa Timur.
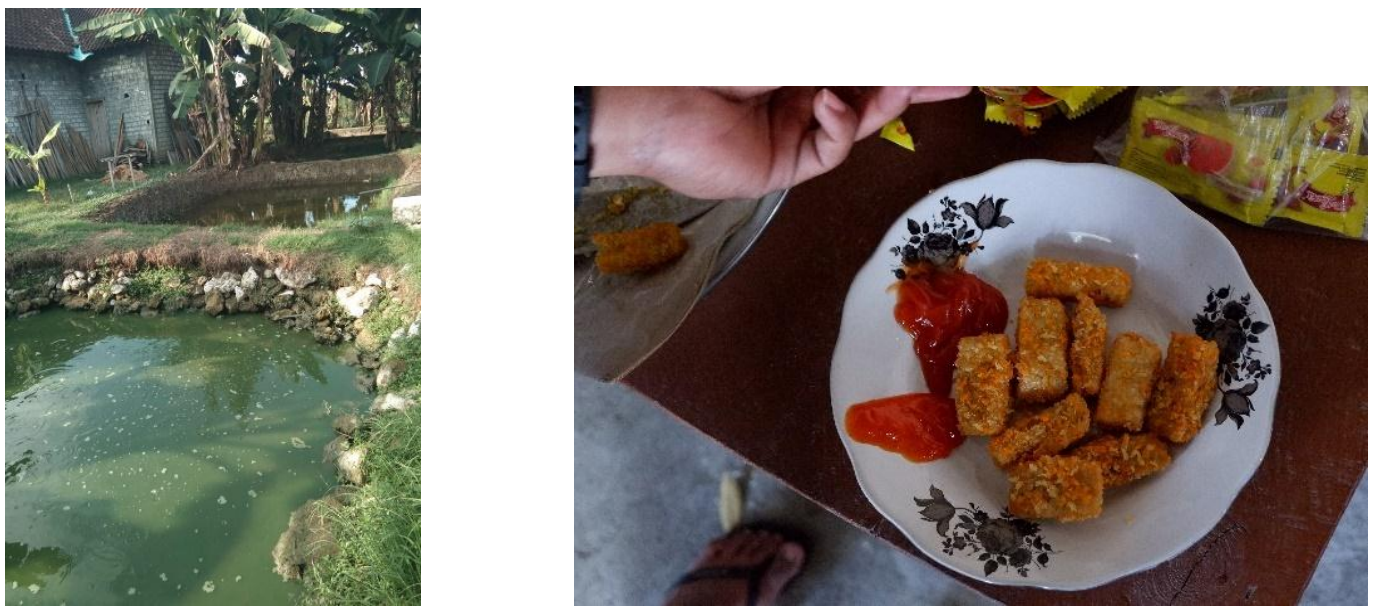

Gambar 5. Kolam Lele dan hasil Olahan Lele berupa Nugget di Dusun Resik 


\section{Pembuatan Kemasan Brown Sugar dan Minyak Kayu Putih}

Di desa Candisari terdapat usaha pengolahan minyak kayu yang didapatkan dari hutan milik PERHUTANI dan diolah oleh warga desa. Keuntungan ynag diperoleh dengan sistem bagi hasil. Guna menaikan harga jual, dalam program ini juga membuat desain kemasa untuk minyak kayu putih. Meskipun hasilnya belum memuaskan namun sudah dapat dijadikan sebagai produk unggulan. Selain itu, terdapat juga pabrik pengolahan tebu menjadi gula, namun hasil gulanya tidak berwarna putih melainkan berwarna coklat sehingga sering dikenal dengan brown sugar. Selama ini hasil produksi dijual dalam bentuk karungan dan belum dikemas untuk jumlah kecil. Oleh karenaitu, produk brown sugar ini dibuatkan kemasan dengan isi $1 \mathrm{~kg}$. meskipun merupakan pabrik yang dikelola oleh individu (Pak Hartono) namun dapat dibanggakan juga sebagai produk lokal.
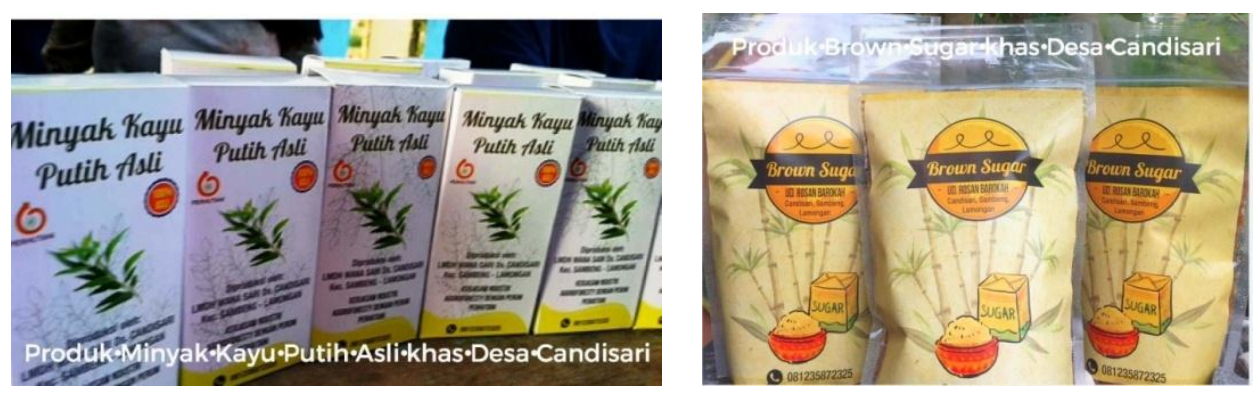

Gambar 6. Kemasan Minyak Kayu Putih dan Brown Sugar

\section{Pembuatan Leaflet Desa Wisata}
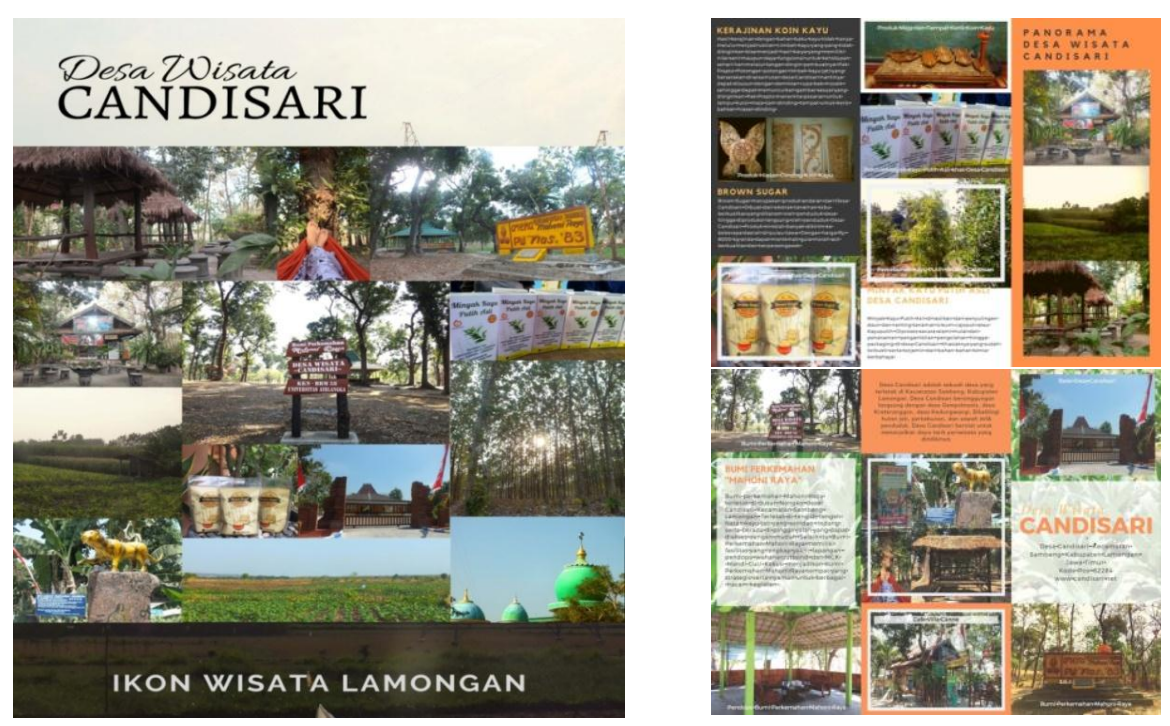

Gambar 8. Leaflet Desa Wisata Candisari 


\section{PENUTUP}

\section{Kesimpulan}

Kegiatan pengembangan desa Candisari menjadi Desa Wisata sangat potensial. Pelaksanaan pengabdian masyarakat ini selain mengoptimalkan yang sudah ada juga memberikan nilai tambah serta mengoptimalkan produksi lokal yang dapat menunjang branding desa wisata. Branding yang dilakukan melalui media online dan media sosial. Selain program branding, dalam pengmas inmi juga membantu masyarakat untuk mengoptimalkan potensi lokal./ kegiatan ini berupa pembangunan fasilitas umum terhadap bumi perkemahan berupa pembangunan pendopo dan toilet (dengan jaringan listrik dan air), pembuatan kemasan untuk hasil produksi kayu putih dan brown sugar, pembuatan rumah jamur beserta log jamur, pengolahan walu untuk pudig, kue, dan nugget, kerajinan tikar pandan dan kayu, serta pendataan terhadap folklore atau cerita rakyat yang bermuatan sejarah. Dari berbagai kegiatan tersebut diharapkan akan menjadikan Desa Candisari ini sebagai salah satu destinasi wisata di Lamongan.

\section{Saran}

Diharapkan kegiatan ini dapat dikembangkan lebih lanjut yakni dengan membentuk jejaring dengan isntansi dan pihak yang terkait baik pemerintah maupun swasta, serta mengadakan event rutin di Desa Candisari.

\section{DAFTAR PUSTAKA}

Arifin B. 2007. Diagnosa Ekonomi Politik Pangan dan Pertanian. Jakarta [ID]: PT. Raja Grafindo Persada

Bagus GN. 1991. Hubungan Pariwisata dengan Budaya di Indonesia: Prospek dan Masalahnya dalam Kumpulan Kongres Kebudayaan. Jakarta: Depdikbud.

Muallisin, Isnaini. 2007. Model Pengembangan Pariwisata Berbasis Masyarakat di kota Yogyakarta. Jurnal Penelitian 02 (2007): 15-23.

Kotler, Philip dan Keller K Lane, (2006). Manajemen Pemasaran, Jakarta: Ghalia .Indonesia.

Spillane JJ. 1993. Ekonomi Pariwisata: Sejarah dan Prospeknya. Yogyakarta: Kanisius.

Surachman,S.A. 2008, Dasar-dasar Manajmen Merek, Malang: Banyumedia,

Tjiptono, Fandy. Gregorius Chandra, Dadi Adriana, 2010, Pemasaran Strategik, Yogyakarta: Andi

Waluyo H. 1993. Dukungan Budaya Terhadap Perkembangan Ekonomi. Jakarta : Departemen Pendidikan dan Kebudayaan. 
Internet:

Peta desa Candisari Sambeng Lamongan Jatim, https://www.google.co.id/maps/place/Candisari,+Sambeng,+Kabupaten+Lamo ngan,+Jawa+Timur/@7.3146953,112.3013338,14z/data=!4m5!3m4!1s0x2e7819199f76ca45:0xb8268 d1c292d88e2!8m2!3d-7.315644!4d112.2920509

Profil desa Candisari http://www.lamongankab.go.id/portal/dokumen-publikmainmenu-31/58-uncategorised/276-candisari.html 